\title{
APLICAÇÃO DO PRINCÍPIO DE VEDAÇÃO AO ENRIQUECIMENTO SEM CAUSA NO ORDENAMENTO JURÍDICO CIVIL BRASILEIRO: O CASO DA SUB-ROGAÇÃO DAS SEGURADORAS
}

\author{
INCIDENCE OF THE PRINCIPLE OF THE UNJUST ENRICHMENT IN BRAZILIAN PRIVATE LAW: \\ THE CASE OF SUBROGATION OF THE INSURER
}

Mario Thiago Moreira*

\begin{abstract}
Resumo:
O presente artigo tem por objetivo analisar a figura jurídica do enriquecimento sem causa, a qual não vem tendo o destaque necessário no Ordenamento Jurídico brasileiro, em detrimento de uma análise profunda e multidisciplinar do tema.

Para melhor compreender a vedação ao enriquecimento sem causa é primordial que se estabeleça o mesmo enquanto princípio informador do ordenamento jurídico civilista no Brasil, vez que tal aplicação torna exponencial os casos em é possível perquirir e utilizar a máxima de vedação ao enriquecimento sem causa. Para tanto, deve-se analisar o que a doutrina estabelece como o conceito de enriquecimento sem causa enquanto figura dúplice, ou seja, figura que atua vez como norma de direito a ser aplicada no caso concreto e vez como princípio informador a ser aplicado na interpretação das demais normas. Para além é necessário percorrer os requisitos do enriquecimento sem causa e seus pressupostos contemporâneos, no intuito de estabelecer a real incidência do enriquecimento sem causa, seja como norma, seja como princípio. Dentre os requisitos tem-se: (i) enriquecimento, (ii) empobrecimento, (iii) ausência de justa causa e (iv) nexo causal.

Derradeiramente, formuladas as premissas acerca do enriquecimento sem causa é possível analisá-lo enquanto princípio à luz de uma caso paradigmático dentro do Código Civil, de 2002. É o caso da sub-rogação da seguradora no direito de ressarcimento do segurado quando de conduta alheia. O objetivo do estudo é demonstrar se tal prerrogativa viola ou não o princípio de vedação ao enriquecimento sem causa.
\end{abstract}

Palavras-chave: Direito das Obrigações. Enriquecimento sem causa. Princípios. Teoria dos seguros. Sub-rogação.

\begin{abstract}
:
This article aims to examine the unjust enrichment, which does not come with the necessary emphasis on the brazilian Legal System. To better understand the prohibition of unjust enrichment is essential to establish the unjust enrichment as principle in civil law in Brazil, so this application becomes exponential, using the maximum ways of unjust enrichment.

To do so, we must analyze what the doctrine establishes by the concept of unjust enrichment as duplicitous figure, (i) as norm of law to be applied in casu and (ii)
\end{abstract}

\footnotetext{
Mestrando em Direito Civil pela Faculdade de Direito da Universidade de São Paulo (FD/USP). Bacharel em Direito pela Faculdade de Direito de Ribeirão Preto da Universidade de São Paulo (FDRP/USP). Advogado.
} 
as a principle to be applied in the interpretation of other rules. It is necessary to go beyond the requirements of unjust enrichment and its contemporary assumptions in order to establish the true incidence of unjust enrichment, either as rule or as principle. Among the requirements we have: (i) enrichment, (ii) depletion, (iii) lack of cause and (iv) causation. With the assumptions about the unjust enrichment is possible to analyze it as a principle used in a paradigmatic case in the Civil Code of 2002. This is the case of subrogation the insurer entitled to reimbursement of the insured when the conduct of others. The objective of the study is to demonstrate if this prerogative violates or not the principle of unjust enrichment.

Keywords: Law of Obligations. Unjust enrichment. Principles. Theory insurance. Subrogation.

\section{Introdução}

O presente artigo tem por objetivo analisar a figura jurídica do enriquecimento sem causa, a qual não vem tendo o destaque necessário no Ordenamento Jurídico brasileiro, em detrimento de uma análise profunda e multidisciplinar do tema.

Para melhor compreender a vedação ao enriquecimento sem causa é primordial que se estabeleça o mesmo enquanto princípio informador do ordenamento jurídico civilista no Brasil, vez que tal aplicação torna exponencial os casos em é possível perquirir e utilizar a máxima de vedação ao enriquecimento sem causa.

Para tanto, deve-se analisar o que a doutrina estabelece como o conceito de enriquecimento sem causa enquanto figura dúplice, ou seja, figura que atua vez como norma de direito a ser aplicada no caso concreto e vez como princípio informador a ser aplicado tanto na interpretação das demais normas no caso concreto quanto nas hipóteses em abstrato, nas quais o próprio ordenamento jurídico é desestabilizado no tocante à sua coesão.

Para além é necessário percorrer os requisitos do enriquecimento sem causa e seus pressupostos contemporâneos, no intuito de estabelecer a real incidência do enriquecimento sem causa, seja como norma, seja como princípio. Dentre os requisitos temse: (i) enriquecimento, (ii) empobrecimento, (iii) ausência de justa causa e (iv) nexo causal.

Derradeiramente, formuladas as premissas acerca do enriquecimento sem causa é possível analisá-lo enquanto princípio à luz de um caso paradigmático dentro do Código Civil, de 2002. É o caso da sub-rogação da seguradora no direito de ressarcimento do segurado quando de conduta alheia.

O objetivo do estudo é demonstrar se tal prerrogativa viola ou não o princípio de vedação ao enriquecimento sem causa. 
2. O enriquecimento sem causa como princípio no Ordenamento Jurídico civil brasileiro

Para Norberto Bobbio, ${ }^{1}$ os princípios gerais de direito estão atrelados ao procedimento de auto integração, sendo normas genéricas do sistema. Confirma, portanto, ser norma o princípio geral, pois é extraído das normas, não podendo ter outra natureza, só sendo extraído das normas para a consecução de definir um caso específico.

Na visão de Ráo, ${ }^{2}$ os princípios gerais de direito são standarts, presunções advindas do próprio ordenamento jurídico, podendo ser derivados do (i) sistema jurídico positivo, ou seja, norma posta, (ii) da ciência do direito que enquanto método permite concluir premissas e (iii) da filosofia do direito, que reúne as inspirações do direito para lhe dar unidade.

A Teoria do Princípio Geral de Direito decorre do pensamento italiano, sendo uma constante no pensamento de Alessandro Graziani, G. B. Castioni e Giuseppe Andreoli, segundo Nanni. ${ }^{3}$ Ademais, o Autor elenca que a fundamentação do enriquecimento sem causa transcorre-se através do princípio formador de direito, qual seja a impossibilidade de se permanecer com o que não se teve motivo ou razão para adquirir, que atua como própria constituição do direito.

Esclarece $\mathrm{Nanni}^{4}$ que, ao contrário do que dispõe a teoria em questão, o enriquecimento sem causa é efetivo mandamento normativo, verdadeiro principio congênito, posto que deriva da ordem constitucional e também civil, firmada pelos princípios de livre-iniciativa, autonomia de vontade e função social do contrato. Novamente, trata-se de não reduzir o significado do enriquecimento sem causa emprestando-lhe uma roupagem que, de fato, descobre-se aquém à suas perspectivas.

Consequentemente à teoria, Capucho ${ }^{5}$ assevera que o princípio deve ser entendido enquanto técnica legislativa, posto que é visto como norma jurídica para a doutrina pós-positivista, devendo ser sistema sopesado com a utilização de princípios e regras, tendo em vista que a unidade do mesmo não estaria prejudicada.

Ademais, o autor tem conceito de enriquecimento sem causa que se aproxima do entendimento deste como princípio. Considera que a vedação ao enriquecimento sem causa preceitua a própria razão da justiça, sendo um princípio jurídico. Desta também deriva, uma vez que decorre do entendimento, à luz da igualdade, liberdade e do princípio

BOBBIO, Norberto. Teoria geral do direito. 2. ed. São Paulo: Martins Fontes, 2008. p. 296-298.

2 RAO, Vicente. O direito e a vida dos direitos. 6. ed. atual. São Paulo: Revista dos Tribunais, 2004. p. 304305.

3 NANNI, Giovanni Ettore. Enriquecimento sem causa. 2. ed. São Paulo: Saraiva, 2010. p. 122.

4 Id. Ibid., p. 124.

5 CAPUCHO, Fábio Jun. O enriquecimento sem causa no código civil brasileiro. 2007. Dissertação (Mestrado) - Faculdade de Direito, Universidade de São Paulo. p. 80-81. 
de dar a cada um o que é seu, da aplicação do ideal de justiça. Assim, é criado um modelo de conduta, reconhecido enquanto dever-ser.

Doravante, liga-se com o princípio da igualdade, sendo deste indissociável, posta sua consecução-fim ser a de garantir a individualidade e liberdade do indivíduo. Neste contexto, só poderia ser observado como fenômeno casuístico, sendo estabelecido enquanto ser, objetivando-se de maneira concreta, já que trata de conceito peculiar da interação social. ${ }^{6}$

Contudo, entender o enriquecimento sem causa como princípio é dificultado pela crítica que, herança do positivismo, imputa à norma posta maior valor do que aos princípios, tornando aqueles a regra geral e estes a subsidiária. Melhor sorte não aguarda argumento, se o princípio for analisado como o próprio fundamento do sistema jurídico, equivalendo-se em autoridade normativa em relação às normas positivadas. ${ }^{7}$

Conclui o autor, ${ }^{8}$ deste modo, que deve haver aplicação concomitante entre princípio e regra, pois há conformação e sustentação entre os mesmos. Até porque, no ordenamento jurídico não é salutar que haja soluções-padrão para todos os casos, devendo ser prevista a maleabilidade no julgar o caso concreto.

Ocorreria então um conflito entre duas vertentes, quais sejam, aqueles que visualizam o juiz como aplicador da lei e aqueles que o visualizam como criador da mesma no caso concreto.

Entender o juiz como mero aplicador da lei, faz pressupor que entre norma e princípio, aquela deve preponderar, com base na obtenção de segurança jurídica, todavia, entender o juiz como criador da norma jurídica faz coexistir em igualdade o princípio e a norma posta. Por isso, finaliza o autor ${ }^{9}$ que a previsão legal do enriquecimento sem causa no art. 884 no Código Civil, de 2002, não exclui sua aplicação como princípio, tendo em vista que esta seria mais ampla do que aquela.

No tocante ao enriquecimento sem causa enquanto princípio geral de direito, elucida Barbiera ${ }^{10}$ que, através da observação de sua construção, indubitavelmente pode-se afirmar o seu caráter geral. A análise histórico/comparativa permite admitir que a figura jurídica modificou seu status desde o Direito Romano, no qual era formulado especificamente nas condictiones, para exsurgir como princípio geral de direito, posto que a manutenção do equilíbrio, fator propulsor do enriquecimento sem causa, está presente enquanto valor tanto no direito privado quanto no direito público. ${ }^{11}$

Id. Ibid., p. 95 .

7 CAPUCHO, Fábio Jun. CAPUCHO, Fábio Jun. O enriquecimento sem causa no código civil brasileiro. 2007. Dissertação (Mestrado) - Faculdade de Direito, Universidade de São Paulo. p. 96-97.

8 Id. Ibid., p. 99.

9 Id. Ibid., p. 100-103.

10 BARBIERA, Lelio. L'ingiustificato arricchimento. Napole, Joveni, 1964. p. 40.

11 Id. Ibid., p. 70/80. 
Para Echeverría, ${ }^{12}$ mais do que propor o preenchimento de um vazio em casos de ausência de contratos ou modo de aquisição, a responsabilidade por enriquecimento sem causa, enquanto princípio geral de direito, delimita suas exceções.

Sobre a falibilidade do princípio, Gordley ${ }^{13}$ indica que a confusão acerca do entendimento do princípio do enriquecimento sem causa faz com que muitos pesquisadores venham a dizer que o princípio seria falho, por muitas vezes não ser respeitado, já que em nenhuma situação deveria alguém se beneficiar da perda ou custo assumido por outrem. Todavia, não é isso que ocorre, é preciso ter em mente que a regra do enriquecimento sem causa apresenta delimitações. A dificuldade repousa no fato de que não é a regra de enriquecimento que traz tais limitações, mas sim são os propósitos de criação de cada direito, como o direito à propriedade, que indicaram os parâmetros do que venha a ser um enriquecimento sem causa.

$\mathrm{Na}$ seara da análise distintiva, Lydia Esteve Gonzalez ${ }^{14}$ diferencia o enriquecimento sem causa enquanto princípio e o enriquecimento sem causa enquanto norma positiva e fonte autônoma de obrigações, uma vez que aquele é um comando negativo que obriga à não-atuar em contrário ao mesmo, enquanto este é um comando positivo de restituir um valor patrimonial. Ademais, o princípio jurídico não apresenta valor a priori, de maneira que sua aplicação decorra sempre que seja necessário proteger o valor intrínseco por ele constituído.

Ao notar a incompletude das teorias tradicionais, bem como a falta de uma teoria acerca do enriquecimento sem causa que fosse proposta por doutrinadores brasileiros, considerando a realidade do ordenamento brasileiro, Giovanni Ettore Nanni propôs uma teoria própria, baseado na concepção sistemática do direito, considerando a análise constitucional do tema, bem como a analise civilista e obrigacional para concluir que o enriquecimento sem causa exsurge enquanto norma e princípio dentro do ordenamento jurídico.

A primeira premissa de Nanni ${ }^{15}$ decorre da falta de estudos acerca das finalidades e objetivos, bem como pressupostos e razões das normas por muito tempo. Tempo este que perdurou durante a supremacia da Escola da Exegese, da simples aplicação

12 ECHEVERRIA, Jose. La responsabilidad fundada en el enriquecimiento injusto y su proyección hacia los problemas ético-jurídicos y políticos. Revista Jurídica de la Universidad Interamericana de Puerto Rico, Santurce, v. 24, n. 2, p. 193-211. p. 211.

13 GORDLEY, James. Foundations of private law: property, tort, contract, unjust enrichment. Oxford: Oxford University Press. p. 419-426.

14 ESTEVE GONZALEZ, Lidia. El enriquecimiento injusto y sin causa y la calificación autonoma del supuesto de hecho del artículo 10.9.III del Codigo Civil Español.Revista de Derecho Privado, Madrid, p. 705-722, oct. 1999. p. 721.

15 NANNI, Giovanni Ettore. Enriquecimento sem causa. 2. ed. São Paulo: Saraiva, 2010. p. 129-138. 
literal da lei, da qual decorria todo o poder. Tal visão foi modificada com a concepção sistemática do Direito, que passou a ser estudado por outra perspectiva filosófica/cultural.

A partir de uma visão sistemática do direito, é possível pensá-lo e moldálo através de preceitos gerais constitucionais, como o Estado Democrático de Direito, a justiça, a segurança jurídica, a dignidade da pessoa humana e a igualdade. É o fenômeno reconhecido como Constitucionalização do Direito Civil. Para o Autor, apenas e tão somente inserindo o Direito Civil adaptado à normativa constitucional pode-se atingir os ideias próprios do Estado, que por sua vez, influenciam sobremaneira o entendimento do enriquecimento sem causa.

\section{Alguns princípios devem ser considerados:}

Como primeiro marco o autor indica a dignidade da pessoa humana. Argumenta que através de tal garantia, o ser humano é protegido dentro de seu valor intrínseco e tudo que a ele corresponde. A partir deste raciocínio, cabe a aplicação do direito civil tendo como perspectiva a pessoa e suas necessidades. A dignidade da pessoa humana seria a relação jurídica inicial, uma vez que considera cada indivíduo dentro de sua própria existência.

Ocorre, portanto, uma mudança paradigmática dentro do direito das obrigações, conhecida como fenômeno da despatrimonialização, e assim o autor sustenta, baseado na teoria de Perlingieri, que com a ruptura do patrimônio e a alçada do valor do personalismo, há de ser repensado o direito das obrigações. Desse modo, há uma restrição à autonomia privada dos sujeitos de direito, pois nenhuma relação jurídica pode ser dissonante da relação jurídica fundamental, isto é, não pode vilipendiar o princípio fundamental da dignidade da pessoa humana. ${ }^{16}$

Para além da primeira acepção da dignidade da pessoa humana, repousa o seu segundo significado, qual seja, a sua relação com a atividade econômica, tanto em sentido estrito quanto em sentido lato. Decorre da previsão expressa do art. 170, caput da Constituição Federal de 1988. Essa interferência ocorreria de maneira direta nos negócios jurídicos, que se enquadram no exercício de atividade econômica em sentido lato.

O segundo marco ou pressuposto é o da liberdade. Baseado na teoria de Canotilho, o Autor $^{17}$ define a liberdade enquanto física, ou seja, poder se locomover ao bel-prazer de seu livre-arbítrio e comportamental, ou seja, poder agir conforme suas e apenas suas convicções. Assim, toda a luta pelo direito demanda liberdade do indivíduo, para que o mesmo possa desvencilhar-se do injusto que se aglomera em sua direção, tolhendo-lhe a plenitude de sua vida. Contudo, tal injusto deve ser motivado, não podendo

16 NANNI, Giovanni Ettore. Enriquecimento sem causa. 2. ed. São Paulo: Saraiva, 2010. p. 145.

17 Id. Ibid., p. 149. 
o indivíduo, sob o pretexto da liberdade, ferir o Estado Democrático e a individualidade de outrem.

Quanto ao terceiro marco, é inerente à qualquer pensamento jurídico, a saber: a justiça. A justiça é um valor intrínseco ao próprio ordenamento jurídico, posto que se não é o fim da jurisdição, pauta-a a ponto de, aos olhos leigos, ser confundida com a mesma. Doravante, a justiça representa dois aspectos de interconexão com o enriquecimento sem causa, quais sejam, a justiça enquanto justiça comutativa, ou seja, reequilibrar uma situação anterior entre aquele que tem e aquele que detêm, num mecanismo de soma zero e a justiça enquanto justiça social, que visa adequar e transmitir padrões de conduta a serem reproduzidos e respeitados em sociedade.

Como quarto marco, tem-se a solidariedade, que nada mais visa do que a proteção do indivíduo, permitindo que este tenha meios plenos para a consecução de seus objetivos. Nesta feita, resume-se enquanto coexistência dos indivíduos e delimitação de possíveis interesses comuns, que devem ser guarnecidos pela teoria do Direito das Obrigações como um todo.

$\mathrm{Na}$ sequência de seu raciocínio, Nanni, ${ }^{18}$ partindo da premissa de necessidade de alargamento do conceito da relação obrigacional, afirma ser cabível um novo comportamento das partes numa relação obrigacional, conforme os princípios da Constituição Federal, de 1988, o que geraria um novo paradigma, não mais composto apenas pela união das singularidades, mas por uma tendência de completude de um todo orgânico que vincule as relações obrigacionais.

Exsurge, assim, deveres acessórios, de proteção e cooperação, gerando uma relação jurídica complexa, notadamente um processo. Supera-se o conceito de relação jurídica simples, de mera prestação e contraprestação, assumindo-se a cooperação dentro de uma relação obrigacional complexa. Segundo Giovanni Ettore Nanni, ${ }^{19}$ a relação obrigacional complexa impõe deveres primários, secundários e laterais às partes, com especial destaque à boa-fé objetiva como comportamento em todos os momentos desse processo. O que ocorreria então não é um embate entre as partes, mas sim um plano conjunto, de cooperação.

Neste segundo plano principiológico, devem ser destacados os princípios da boa-fé objetiva, na sua função interpretativa e delimitadora, do equilíbrio econômico e da função social do contrato, na face individual e a face coletiva.

Visitadas as premissas do pensamento do Autor, chega-se à conclusão de que no ordenamento jurídico atual, a regra que impede o enriquecimento sem causa é imprescindível. Partindo das premissas genéricas constitucionais, a teoria de Giovanni

18 NANNI, Giovanni Ettore. Enriquecimento sem causa. 2. ed. São Paulo: Saraiva, 2010. p. 154.

19 Id. Ibid., p. 158. 
Ettore Nanni vai além da simples consideração do enriquecimento sem causa como efeito da própria justiça comutativa, desenvolvendo todo o raciocínio constitucional e civilista que fazem com que o enriquecimento sem causa tenha seu lugar cativo no ordenamento pátrio.

Derradeiramente, o doutrinador afirma que, em pese a dificuldade de caracterizar a natureza jurídica do enriquecimento sem causa, tendo em vista as teorias divergentes apresentadas até então, a melhor opção seria traduzi-lo como sendo de caráter dúplice: ora princípio, ora fonte obrigacional.

O enriquecimento sem causa é fonte obrigacional, posto que inserido nos arts. 884 à 886 do Código Civil, de 2002, dando origem à uma obrigação que pode ser pretensa através da ação de enriquecimento. Este seria o aspecto mais convencional do instituto.

Por outro lado, considerando o sistema jurídico atual, o enriquecimento sem causa serviria também como meio de propagação de sua própria premissa, enquanto princípio regente das obrigações. De acordo com Nanni, ${ }^{20}$ não havendo contrariedade da lei, o princípio poderia ser utilizado em qualquer relação jurídica de natureza obrigacional.

Por fim, alude o Autor ao fato de que o enriquecimento sem causa deveria ser considerado cláusula geral, ${ }^{21}$ tendo em vista a amplitude que dará o legislador ao Poder Judiciário na utilização do enriquecimento sem causa se este for considerado cláusula geral.

Também em consonância ao tema, Michelon Jr., ${ }^{22}$ ressalta que derivado do fato do enriquecimento sem causa ser previsto enquanto cláusula geral pode-se infirmar duas considerações, quais sejam, (i) o princípio irradia seus efeitos para os demais institutos de direito privado o que gera uma função estruturante e (ii) funciona como fonte residual de obrigações no direito civil. Importa salientar, adiante, que sua previsão como cláusula geral permite uma abertura ou ampliação no seu uso e aplicação.

Percebe-se, portanto, que a Doutrina brasileira aponta o enriquecimento sem causa como princípio informador do direito civil pátrio, o que sugere que o mesmo deve ser aplicado na própria construção das normas de direito civil. Isso porque é necessário que o ordenamento guarde a devida coesão entre suas normas e princípios.

20 NANNI, Giovanni Ettore. Enriquecimento sem causa. 2. ed. São Paulo: Saraiva, 2010. p. 175.

21 Id. Ibid., p. 178.

22 MICHELON JR, Claudio. Direito restitutório: enriquecimento sem causa, pagamento indevido e gestão de negócios. São Paulo: Revista dos Tribunais, 2007. p. 180-181. 


\section{Requisitos do enriquecimento sem causa}

Para que haja aplicação e a identificação do direito material no caso concreto, é preciso que a doutrina e o legislador esbocem pressupostos e requisitos que permitirão coincidir os atos cotidianos com a tutela jurídica. Trata-se de uma análise extremamente factual, alinhada aos costumes e tendências de determinado povo que segue determinados preceitos, sendo, assim, circunstância de seu próprio tempo.

Duas foram as formas encontradas ao longo da história para identificar o enriquecimento sem causa e posterior ajuizamento da ação de enriquecimento, a saber: a corrente alemã e a corrente francesa. A corrente alemã, partindo da premissa de que o enriquecimento sem causa já era previsto em seu ordenamento, não apresentava requisitos tão rígidos para a tipificação do enriquecimento sem causa. Já a corrente francesa, forjada no ritmo da casuística, fez com que sua doutrina torna-se imprescindível a tipificação de pressupostos para a análise do enriquecimento sem causa.

Coube aos agentes do Direito brasileiro seguirem os preceitos franceses, herdados no balanço cultural que permeou gerações de pensadores filiados muito mais ao pensamento francês que ao pensamento alemão. Assim, fixaram como pressupostos: (i) enriquecimento, (ii) empobrecimento, (iii) nexo de causalidade (iv) ausência de justa causa e (v) subsidiariedade da ação de enriquecimento.

$\mathrm{Na}$ Doutrina portuguesa, Varela ${ }^{23}$ indica que são pressupostos para que seja configurado o enriquecimento sem causa os seguintes: (i) enriquecimento, (ii) carência de causa justa e (iii) obtenção à custa de outrem. Aproxima-se, portanto, da visão mais ampla do enriquecimento sem causa, desconsiderando quesitos de empobrecimento e nexo de causalidade, estes mais específicos.

\subsection{Enriquecimento}

O primeiro pressuposto para que haja enriquecimento sem causa é decorrência óbvia do instituto, notadamente trata-se do enriquecimento. Enriquecer, em linhas gerais, seria obter vantagem que se traduza em modificação do status quo ante do enriquecimento na medida em que se encontrada em melhor situação do que a anterior. Percebe-se o quão vaga é a explicação supra, mas há razão para o ser. Explica-se:

Não é claro um conceito definitivo do que se seria enriquecer para a teoria do enriquecimento sem causa. É uma figura ampla, o que levou Nanni ${ }^{24}$ a dizer que trata-

\footnotetext{
23 ANTUNES VARELA, João de Matos. Das obrigações em geral. 3. ed. Coimbra: Livraria Almedina, 1970. p. 318.

24 NANNI, Giovanni Ettore. Enriquecimento sem causa. 2. ed. São Paulo: Saraiva, 2010. p. 235.
} 
se de conceito elástico e indeterminado, cuja definição no caso concreto dependerá das vicissitudes da situação hipotética submetida à apreciação. Assim, para o autor são possibilidades de enriquecimento (i) o proveito obtido, (ii) a diminuição do passivo, também denominado enriquecimento negativo, e (iii) a vantagem não patrimonial.

O legislador brasileiro ao elaborar o artigo 884 do Código Civil omitiu qualquer óbice ao entendimento de enriquecimento, podendo ser entendido que o mesmo pode ocorrer de qualquer maneira, desde que possa ser objetivamente comprovado a fim de demonstrar o ganho de um e a perda de outrem. Nestes termos, Nanni ${ }^{25}$ salienta que o enriquecimento deve consubstanciar-se num dado objetivo, numa vantagem concreta, permitindo a sua identificação para o exercício da ação de enriquecimento em busca de extrair-se das mãos do enriquecido o produto que foi indevidamente auferido.

Apesar de ser pressuposto fundamental à identificação do enriquecimento sem causa no caso concreto, o enriquecimento não pode ser considerado sob um ponto de vista absoluto. Isto porque o ato de enriquecimento ocorre a todo o momento dentro de uma sociedade dinâmica, tendo em vista que o próprio sistema de trocas comerciais não tem caráter exauriente, mas sim de auferir lucro aos seus participantes. De tal modo, o simples ato de enriquecer nada significa e deve ser sopesado com os demais pressupostos, como falta de justo motivo, empobrecimento da outra parte e nexo causal entre os atos.

Prosseguindo, o enriquecimento pode ter natureza positiva ou negativa. Quando de natureza positiva, transparece num deslocamento de riqueza que aumente a balança patrimonial do enriquecimento em relação ao estado anterior, modificando os números absolutos numa majoração do resultado.

Quando de natureza negativa, se perfaz através de uma relação jurídica que aumente a balança patrimonial do enriquecido, mas não numa relação de incremento e sim numa desconstituição de situação prejudicial, desse modo, retirando ônus que era conferido à balança patrimonial do enriquecido como, por exemplo, no caso de diminuição do valor de uma dívida do mesmo para com o empobrecido.

Neste contexto específico, Michelon $\mathrm{Jr}^{26}{ }^{26}$ considera que a noção empregada de enriquecimento no contexto do enriquecimento sem causa é eminentemente normativa, não podendo ser considerada apenas num aspecto fático.

Para chegar a tal entendimento, Michelon $\mathrm{Jr}^{27}$ parte da divisão entre enriquecimento objetivo e enriquecimento subjetivo, considerando que o primeiro trata do valor absoluto do bem em questão, enquanto o segundo trata do valor realmente

\footnotetext{
25 NANNI, Giovanni Ettore. Enriquecimento sem causa. 2. ed. São Paulo: Saraiva, 2010. p. 236.

26 MICHELON JR, Claudio. Direito restitutório: enriquecimento sem causa, pagamento indevido e gestão de negócios. São Paulo: Revista dos Tribunais, 2007. p. 184-185.

27 Id. Ibid., p. 187-191.
} 
aproveitado perante o enriquecido. Pela interpretação gramatical da norma não é possível consolidar a posição do legislador, todavia, como o Código Civil, de 2002, deriva de um entendimento de abertura de suas estruturas frente o caso concreto, melhor seria, na visão do Autor, fosse aplicado como critério o enriquecimento subjetivo.

A fim de calcular o montante do enriquecimento, pondera Michelon Jr., ${ }^{28}$ que o mesmo poderia ser efetuado considerando a soma bruta ou a soma líquida do mesmo, sendo que aquela baseia-se tão somente nos valores auferidos enquanto que esta presume e abate as despesas provenientes daquele bem. Adotando-se o cálculo do enriquecimento líquido pode ser que o mesmo seja negativo, o que redundaria na não-aplicação do artigo 884 do Código Civil brasileiro.

Quanto ao enriquecimento este trataria de vantagem de caráter patrimonial, que poderia ser adquirida através do aumento do ativo, diminuição do passivo, uso ou consumo de coisa alheia ou no exercício de direito alheio ou então poupança de despesas. Tal vantagem pode ser considerada sob um viés objetivo, levando-se em conta o enriquecimento real, caracterizado pelo aumento concreto do patrimônio, em valores absolutos, ou o enriquecimento patrimonial, caracterizado pelo aumento hipotético do patrimônio do enriquecido, considerando o que o mesmo estaria disposto a gastar para compor situação fática equivalente àquela. ${ }^{29}$

De maneira condizente com a linha geral exposta, Vieira Gomes ${ }^{30}$ acredita que a visão tradicional do enriquecimento sem causa, fixada na noção de transmissão de valor não é a mais completa. Parte dessa imprecisão pelo fato de que a simples transmissão não explica casos de enriquecimento sem causa por fato de terceiro ou por caso fortuito.

Para Vieira Gomes ${ }^{31}$ a deslocação patrimonial não explica os casos em que há enriquecimento por utilização de bem alheio, nem que se generalize o caso a partir da poupança de gasto gerado pelo uso de bem de terceiro.

A questão premente do enriquecimento sem causa se encontra na discussão de a mesma ser preconizada numa teoria unitária ou numa teoria aberta. Vieira Gomes ${ }^{32}$ discorre que a primeira, em que pese dar maior base ao instituto, gera um alto teor de generalidade e abstratividade, o que impede a aplicação real. Já no caso da teoria aberta,

28 MICHELON JR, Claudio. Direito restitutório: enriquecimento sem causa, pagamento indevido e gestão de negócios. São Paulo: Revista dos Tribunais, 2007. p. 193-194.

29 ANTUNES VARELA, João de Matos. Das obrigações em geral. 3. ed. Coimbra: Livraria Almedina, 1970. p. 319 .

30 VIEIRA GOMES, Júlio Manuel. O conceito de enriquecimento, o enriquecimento forçado e os vários paradigmas do enriquecimento sem causa. Coimbra: Coimbra Editora, 1998. p. 170.

31 Id. Ibid., p. 174.

32 Id. Ibid., p. 178. 
ao tratar do tema de forma fragmentada o problema seria a complexidade que o instituto assumiria.

$\mathrm{Na}$ prerrogativa quantitativa do tema, Vieira Gomes ${ }^{33}$ acredita que o enriquecimento sem causa deve ser pautado no valor do enriquecimento real quando da restituição, sendo facultado o enriquecimento patrimonial quando houver boa-fé por parte do enriquecido.

Fundamental distinção é trazida por Serpa $\operatorname{Lopes}^{34}$ ao lembrar que o enriquecido não pode ter agido com culpa, caso contrário estar-se-ia diante de caso de responsabilidade civil e não de enriquecimento sem causa, o que daria ensejo à reparação por dano. Entretanto, no tocante à boa-fé ou má-fé, pouco importa para a configuração do enriquecimento sem causa em qual delas concentravam-se os atos do enriquecido.

$\mathrm{Na}$ obra de Washington de Barros Monteiro, ${ }^{35}$ depreende-se que o enriquecimento só pode ter como base, ou causa, a lei ou o contrato, caso contrário, seria este considerado locupletamento injustificado.

Para Serpa Lopes, ${ }^{36}$ a questão do deslocamento patrimonial, deve ser vista sob uma ótica dual, podendo o mesmo ocorrer através de uma causa habilitante ou de uma causa justificante. No caso de uma causa habilitante, a falta da mesma acarreta em necessária nulidade do negócio jurídico, tendo em vista sua natureza. Já no caso da causa justificante, a sua descaracterização torna ainda válido o deslocamento, para fins de direito, mas não para a relação entre as partes, por isso, caberia o enriquecimento sem causa.

$\mathrm{Na}$ doutrina também há questionamento acerca da possibilidade ou-não do enriquecimento não-patrimonial ou enriquecimento moral. Quanto à isto existem três pensamentos diversos, como demonstra o pensamento de Nanni: ${ }^{37}$ (i) pode-se considerar que o enriquecimento sem causa só pode ser proveniente de deslocamento patrimonial, refutando, portanto, a possibilidade de enriquecimento moral como fonte de reestabelecimento do estado anterior. Entre os adeptos de tal teoria estão os doutrinadores italianos; (ii) pode-se considerar a possibilidade sim do incremento moral ser considerado como enriquecimento, fazendo com que haja casos de enriquecimento sem causa de cunho moral; e, por fim, (iii) pode-se considerar a possibilidade do enriquecimento mora ocorrer

33 VIEIRA GOMES, Júlio Manuel. O conceito de enriquecimento, o enriquecimento forçado e os vários paradigmas do enriquecimento sem causa. Coimbra: Coimbra Editora, 1998. p. 203.

34 LOPES, Miguel Maria de Serpa. Curso de direito civil: fontes acontratuais das obrigações - responsabilidade civil. 4. ed., rev. e atual. Rio de Janeiro: Freitas Barros, 1995. p. 84. 5v.

35 MONTEIRO, Washington de Barros. Curso de direito civil: direito das obrigações. rev. e atual. São Paulo: Saraiva, 2003. p. 441. 5v.

36 LOPES, Miguel Maria de Serpa. Curso de direito civil: fontes acontratuais das obrigações - responsabilidade civil. 4. ed., rev. e atual. Rio de Janeiro: Freitas Barros, 1995. p. 72.

37 NANNI, Giovanni Ettore. Enriquecimento sem causa. 2. ed. São Paulo: Saraiva, 2010. p. 239-243. 
apenas e tão somente no caso de possibilidade de constatação material deste incremento, ou seja, o mesmo deve ser mensurável pecuniariamente.

Entre os adeptos desta teoria estão os doutrinadores franceses e Giovanni Ettore Nanni, ${ }^{38}$ que analisa iniludivel a permanência de teor econômico, além de definir haver vantagem obtida e cunho patrimonial no enriquecimento moral.

$\mathrm{O}$ autor $^{39}$ também sustenta outro argumento a favor da consideração do enriquecimento moral, qual seja, a incidência do princípio da dignidade da pessoa humana e os correlatos da Constituição Federal, bem como a receptividade da teoria da despatrimonialização do direito civil, para concluir dá possibilidade de haver enriquecimento moral.

$\mathrm{O}$ enriquecimento moral também é considerado por Caramuru ${ }^{40}$ que o denomina enriquecimento por aspectos qualitativos.

$\mathrm{Na}$ visão ampla de atribuições patrimoniais preconizada por Varela, ${ }^{41} \mathrm{o}$ enriquecimento sem causa só realiza-se enquanto fenômeno quando de uma atribuição patrimonial, mas esta pode ser decorrente de todas as situações por virtude das quais uma pessoa obtém certa vantagem de natureza patrimonial a expensas de outra, independentemente da natureza do ato donde elas procedem.

$\mathrm{Na}$ justificativa de Serpa Lopes, ${ }^{42}$ este adere ao pensamento do enriquecimento enquanto fenômeno material e também moral, uma vez que o mesmo, por exemplo na forma de ensino, traz incremento ao enriquecido, bem como o material de fato.

Partindo do pressuposto do enriquecimento moral como proveito de um prestação que seja suscetível de apreciação econômica, Michelon $\mathrm{Jr}^{43}$ concorda com a possibilidade, através da interpretação do instituto no Direito brasileiro, de aplicação do enriquecimento sem causa nos casos de enriquecimento moral, uma vez que é possível mensurar tal valor econômico e, ademais, caso assim não fosse, em alguns casos estaria a parte desamparada, uma vez que sem o enriquecimento moral, apelaria para a gestão de negócios, a qual não abarca todas as possibilidades, já que à mesma é imprescindível o fator altruísta.

38 NANNI, Giovanni Ettore. Enriquecimento sem causa. 2. ed. São Paulo: Saraiva, 2010. p. 243.

39 Id. Ibid., p. 244.

40 FRANCISCO, Caramuru Afonso. O enriquecimento sem causa nos contratos. In: BITTAR, Carlos Alberto (Org.). Contornos atuais da teoria dos contratos. São Paulo: Revista dos Tribunais, 1993. p. 82.

41 VARELA, Antunes. Direito das obrigações: conceito estrutura e função da relação obrigacional, fontes das obrigações, mobilidades das obrigações. Rio de Janeiro: Forense, 1977. p. 194.

42 LOPES, Miguel Maria de Serpa. Curso de direito civil: fontes acontratuais das obrigações - responsabilidade civil. 4. ed., rev. e atual. Rio de Janeiro: Freitas Barros, 1995. v. 5, p. 71.

43 MICHELON JR, Claudio. Direito restitutório: enriquecimento sem causa, pagamento indevido e gestão de negócios. São Paulo: Revista dos Tribunais, 2007. p. 194-195. 


\subsection{Empobrecimento}

O segundo pressuposto para a configuração material do enriquecimento sem causa é o empobrecimento. Significa que na medida em que há um enriquecimento de alguém, deve haver um empobrecimento de outrem, caso contrário, não haveria consolidação do instituto. Neste sentido, o empobrecimento assume função de complementariedade, ou seja, atua permitindo que se atinja o significado total do enriquecimento sem causa, completando a deslocação de patrimônio.

Todavia, embora seja fácil reconhecer o empobrecimento quando o empobrecido realiza ato próprio que lhe diminua o patrimônio, fica mais difícil a constituição do mesmo em casos limítrofes. Neste caso, exemplifica Nanni, ${ }^{44}$ os casos de economia de despesas e prestação de serviços como sendo difíceis de visualização.

Resultam-se, assim, duas formas de ocorrer o empobrecimento sendo que a primeira e mais comum se dá de maneira visível, como exemplo se tem a realização de despesa direta e a segunda ocorre de maneira não visível, exemplificada na prestação de serviço.

Ademais, pode ocorrer um terceiro caso, excepcional, que o da inexistência do empobrecimento. Segundo Nanni, ${ }^{45}$ pode haver inexistência do empobrecimento no caso de fato que gera o enriquecimento, mas que seja imensurável no tocante ao empobrecimento. Seria o caso de sujeito que presta informação de grande valia para o enriquecido, contudo, não tem qualquer perda relativa à mesma. Assim, conclui-se, que, em certos casos, pode não haver a incidência do empobrecimento para que haja configuração do enriquecimento sem causa.

Também não seria caso de existência de empobrecimento quando das vantagens não patrimoniais, ${ }^{46}$ que não afetam materialmente os sujeitos, mas como já visto, são consideradas como causas de enriquecimento sem justo motivo. Por isso, a conclusão de não ser requisito absoluto o empobrecimento.

É preciso, para melhor entender o pressuposto do empobrecimento, revisitar o mens lege que pautou o legislador, quando dá normatização do enriquecimento sem causa no ordenamento jurídico brasileiro. Estatuiu o legislador que deve haver restituição do obtido sem justa causa à custa de outrem. O termo utilizado foi à custa de outrem, no mesmo sentido dos Códigos Português e Alemão, que transparece amplitude elevada, logo, não haveria por que restringir apenas à causa do empobrecimento as possibilidades

\footnotetext{
44 NANNI, Giovanni Ettore. Enriquecimento sem causa. 2. ed. São Paulo: Saraiva, 2010. p. 253.

45 Id. Ibid., p. 254.

46 Id. Ibid., p. 255.
} 
de restituição. Por isso conclui $\mathrm{Nanni}^{47}$ que não é caso de excluir o pressuposto do empobrecimento, mas ponderar a sua aplicação, podendo dispensá-lo em determinadas situações.

Também Varela ${ }^{48}$ já entendia ser a expressão à custa de outrem mais ampla do que o sentido de enriquecimento em decorrência de empobrecimento de outrem.

Neste mesmo sentido tem-se Michelon $\mathrm{Jr}^{49}$ que diz no sentido contrário à utilização do termo empobrecimento, uma vez que a opção do legislador brasileiro foi pelo termo genérico "a custa de outrem". Sob esse viés, existiriam duas formas do enriquecimento ocorrer a custa de outrem, a saber, (i) com a efetiva diminuição patrimonial e (ii) sem a efetiva diminuição patrimonial.

Ocorreria com a efetiva diminuição patrimonial sempre que decorresse de uma perda efetiva, como a destruição de um direito ou a diminuição do valor do mesmo ou de um ganho evitado, como no caso de prestação de um serviço não contratado. Já no caso de ocorre ocorrência sem a efetiva diminuição patrimonial estar-se-ia diante dos casos de enriquecimento por intromissão ou intervenção. Importante ressaltar que nestas situações é imprescindível a teoria abrangente do enriquecimento sem causa, uma vez que, caso contrário, não seria possível resolver o injusto enquanto responsabilidade civil, devido à dificuldade de se estimar o dano em casos de intromissão, como no exemplo do autor em que um terreno alheio é utilizado como depósito de materiais por alguns meses. ${ }^{50}$

Quanto à necessidade do enriquecimento ser obtido à custa de outrem, define $\operatorname{Varela}^{51}$ que o mesmo deve atingir aquele que postula a restituição mediante enriquecimento sem causa. Assim, deve haver uma perda de outrem que, todavia, não necessariamente se equivale ao aumento de patrimônio do enriquecido, por exemplo no caso de instalação em casa alheia. Por causa desta amplitude de possibilidades, substituiu o legislador alemão a expressão com seu patrimônio (aus dem Vermögen eines anderen), por à sua custa (auf dessen Kosten), o que inspirou o legislador português.

Todavia, poderia ocorrer ocasião em que não fosse diminuído o patrimônio do credor do enriquecimento, nem potencialmente impedido de aumento como, por exemplo, no caso daquele que utiliza casa alheia, mas o credor não estava disposto a alugar a mesma. Diante deste impasse, tendente à não permitir a utilização e aproveitamento

47 NANNI, Giovanni Ettore. Enriquecimento sem causa. 2. ed. São Paulo: Saraiva, 2010. p. 257.

48 VARELA, Antunes. Direito das obrigações: conceito estrutura e função da relação obrigacional, fontes das obrigações, mobilidades das obrigações. Rio de Janeiro: Forense, 1977. p. 205.

49 MICHELON JR, Claudio. Direito restitutório: enriquecimento sem causa, pagamento indevido e gestão de negócios. São Paulo: Revista dos Tribunais, 2007. p. 197.

$50 \quad$ Id. Ibid., p. 198/199.

51 ANTUNES VARELA, João de Matos. Das obrigações em geral. 3. ed. Coimbra: Livraria Almedina, 1970. p. 326-327. 
injusto de bens alheios, Varela ${ }^{52}$ bem define que vantagem patrimonial é obtida à custa de outrem por ser obtida com meios ou instrumentos pertencentes outrem.

Acrescenta o autor ${ }^{53}$ que ao perfilar tal raciocínio, a lei comungaria com a doutrina alemã da destinação ou da afetação (Zuweisungslehre) dos direitos absolutos, uma vez que a mesma propõe que os direitos reais, para além de direitos de exclusão impedindo a ingerência de terceiros ao bem, são direitos que conferem ao titular o respectivo provento econômico resultante de sua utilização, fruição, entre outros atos. Assim, mesmo que não pretendesse utilizar-se daquele determinado viés relativo ao bem, este lhe cabia de direito.

De maneira conclusiva, Fernando Noronha ${ }^{54}$ credita à teoria da destinação dos bens o fundamento mais preciso para a vedação ao enriquecimento sem causa. Como motivo para tanto tem-se que ao repousar seu significado apenas sobre a equidade, o enriquecimento sem causa seria considerado apenas um remédio excepcional, contudo, ao ser elencado como representação da teoria da destinação dos bens, teria papel ordinário no ordenamento, pois permitiria não deixar aquele ao qual não é atribuído o direito dele se aproveitar economicamente.

Vale notar que Hildebrand ${ }^{55}$ considera, levando em conta os pressupostos de empobrecimento e nexo causal como desnecessários, que o pressuposto do enriquecimento à custa de outrem adquire maior relevância na teoria, uma vez que este seria o liame mais correto para tipificar o enriquecimento sem causa. A expressão mais ampla faz com que não seja necessária a diminuição patrimonial efetiva por parte do polo prejudicado.

Fica esclarecido, na dissertação de Hildebrand, ${ }^{56}$ que a justa causa prevista no art. 884 não está adstrita à simples atribuição patrimonial, mas sim tem incidência em dois outros aspectos, a saber: (i) no uso de bem e direito deve ser observada a justa causa para tanto e (ii) nos casos de acréscimo de valor de um bem, este deve ter justa causa do mesmo modo.

Em boa hora, Serpa Lopes ${ }^{57}$ adverte que só haverá enriquecimento sem causa se o enriquecimento partiu de ato sem demonstração de vontade ou de culpa por

\footnotetext{
52 ANTUNES VARELA, João de Matos. Das obrigações em geral. 3. ed. Coimbra: Livraria Almedina, 1970. p. 329.

53 Id. Ibid., p. 329/330.

54 NORONHA, Fernando. Enriquecimento sem causa. Revista de Direito Civil, Imobiliário, Agrário e Empresarial, São Paulo, v. 15, n. 56, p. 51-78. p. 57.

55 HILDEBRAND, Lucas Fajardo Nunes. Pressupostos da obrigação de restituir o enriquecimento sem causa no código civil brasileiro. 2010. Dissertação (Mestrado) - Faculdade de Direito, Universidade de São Paulo, São Paulo. p. 72.

56 Id. Ibid., p. 63.

57 LOPES, Miguel Maria de Serpa. Curso de direito civil: fontes acontratuais das obrigações - responsabilidade civil. 4. ed., rev. e atual., Rio de Janeiro: Freitas Barros, 1995. v. 5, p. 83.
} 
parte do empobrecido, uma vez que a presença de vontade do mesmo demonstraria assentimento e concatenaria um ato de mera liberalidade.

\subsection{Nexo de causalidade}

Como terceiro pressuposto do enriquecimento sem causa, tem-se o nexo de causalidade. Trata-se de verdadeira junção, aglutinação, entre o enriquecimento e o empobrecimento. Seria uma espécie de liame factual que permite identificar a comunhão temporal e espacial dos atos que geram enriquecimento e empobrecimento.

Não se trata, entretanto, do típico nexo de causalidade da responsabilidade civil, que necessita da conduta ilícita e culposa do agente, gerando obrigação de reparar o dano e ressarcir eventuais lucros cessantes danos de outras naturezas. É bem verdade, que equivale à uma mera causa que liga ambas as condutas, sem grandes requisitos ou condições.

O nexo de causalidade pode ser direto ou indireto, ${ }^{58}$ o que significa dizer que ao ser direto, traz a união entre empobrecido e enriquecido pelo liame de fato que comprova o deslocamento patrimonial ou moral. Por outro lado, ao ser considerado indireto, pressupõe-se os casos em que há hipótese de enriquecimento indireto, ou seja, enriquecimento de terceiro, como já foi aludido no presente trabalho.

No tocante à requisitos, Nanni ${ }^{59}$ define que o nexo de causalidade deve respeitar a existência de relação de causa e efeito entre enriquecimento e um fato, o que permite entender o nexo mesmo que não haja empobrecimento.

Acerca do nexo causal como pressuposto do enriquecimento sem causa, afirma Michelon $\mathrm{Jr}^{60}{ }^{6}$ que o mesmo significa simplesmente que o enriquecimento possa explicar o empobrecimento, não havendo a mesma carga lógica do nexo causal no tocante à responsabilidade civil. Esse liame é facilmente entendido quando se remonta à concepção de transferência de patrimônio que o enriquecimento sem causa teve por muito tempo, mas que atualmente se encontra fadada ao desuso, tendo em vista formas outras de enriquecimento que prescindem da deslocação, como o por intromissão.

Quanto à necessidade de nexo direto (imediato), caso do deslocamento patrimonial simples entre as partes ou nexo indireto (mediato), caso do deslocamento complexo, que passa por terceiro, Michelon $\mathrm{Jr}^{61}$ entende não haver qualquer óbice para

58 NANNI, Giovanni Ettore. Enriquecimento sem causa. 2. ed. São Paulo: Saraiva, 2010. p. 258.

59 Id. Ibid., p. 261.

${ }^{60}$ MICHELON JR, Claudio. Direito restitutório: enriquecimento sem causa, pagamento indevido e gestão de negócios. São Paulo: Revista dos Tribunais, 2007. p. 206.

$61 \quad$ Id. Ibid., p. 207. 
que ambos sejam considerados válidos quando da atribuição do enriquecimento sem causa, uma vez que creditar eficácia apenas aos casos de nexo direto seria menos abrangente.

Cabe estabelecer o parâmetro da crítica de Hildebrand ${ }^{62}$ no caso do pressuposto do nexo causal. Este serviria única e exclusivamente dentro de uma cadeia lógica que se funda-se sob os auspícios do empobrecimento como pressuposto do enriquecimento sem causa. Como tal entendimento pode ser superado pela nova concepção de enriquecimento sem causa, seria inadequado se falar em nexo causal, posto este pressuposto depender da existência de outro pressuposto.

Segundo Barbiera, ${ }^{63}$ a relação de causalidade entre enriquecimento e dano não deve ser analisada como comumente, ou seja, um sendo a causa do outro, mas sim com a premissa de que o enriquecimento deve ser consequência do dano.

\subsection{Ausência de justa causa}

Ausência de justa causa é o quarto pressuposto do enriquecimento sem causa e reputa-se como relevante à medida que não sendo configurado, não há de se falar em enriquecimento sem causa, mas em, apenas e tão somente, enriquecimento de alguém tendo em vista relação factual com outrem.

Cabe destacar que Giovanni Ettore Nanni ${ }^{64}$ estuda o tema a partir da premissa da diferenciação entre causa como elemento do contrato e causa como motivação que impede a configuração do enriquecimento sem causa. Em síntese, o Autor contrasta os argumentos causalistas e anticausalistas para definir que não se trata da mesma causa no caso do enriquecimento sem causa, mas sim que neste o que se necessita é uma formatação mais ampla, mais uma vez considerando que por vezes o enriquecimento sem causa se dá por questões não-patrimoniais ou morais.

Diz o Autor que ainda que seja possível, mesmo que em tese, discutir acerca da causa como elemento do negócio jurídico, ela, no enriquecimento indevido, não se liga a um negócio, mas a um fato a ser aferido na hipótese concreta. ${ }^{65}$ Assim, bastaria uma apreciação simples que levaria ao motivo, tornando-se motivação fático-hipotética, longe do estrito negócio.

Impossível, portanto, uma teoria unitária e genérica que leve a um rol taxativo de causas de enriquecimento. Falta, simplesmente, fundamentar o enriquecimento, com

\footnotetext{
62 HILDEBRAND, Lucas Fajardo Nunes. Pressupostos da obrigação de restituir o enriquecimento sem causa no código civil brasileiro. 2010. Dissertação (Mestrado) - Faculdade de Direito, Universidade de São Paulo, São Paulo. p. 72.

63 BARBIERA, Lelio. L'ingiustificato arricchimento. Napole: Joveni, 1964. p. 8.

64 NANNI, Giovanni Ettore. Enriquecimento sem causa. 2. ed. São Paulo: Saraiva, 2010. p. 262.

65 Id. Ibid., p. 267.
} 
qualquer título jurídico ou legitimidade legal. Possível seria elencar os principais grupos genéricos que podem gerar a causa do enriquecimento, quais sejam, (i) lei, (ii) decisão legal, (iii) ato jurídico e (iv) fato social.

Aliás, é até importante a indefinição do conceito de causa, uma vez que aliada com o critério de subsidiariedade do enriquecimento sem causa, pode fazer com que o instituto seja usado de acordo com que o ordenamento seja manipulado. Em outras palavras, cada vez que uma causa seja subtraída numa relação jurídica, será capaz o enriquecimento sem causa de atuar na reconstituição do injusto.

De se ressaltar também que a falta de causa pode ser anterior ou posterior, de acordo com o que dispõe o art. 885 do Código Civil, de 2002. Será anterior quando a causa não existia antes do ato que gera o enriquecimento sem causa, como no caso daquele que transfere mais dinheiro do que devido ao enriquecido. Será posterior quando a causa deixar de existir de maneira superveniente, como um aluguel por tempo determinado, no qual o locatário continua a utilizar o imóvel; neste caso, até o termino do contrato havia causa, mas deixou de existir com a resolução do mesmo.

Ademais, indica Antonio Junqueira de Azevedo ${ }^{66}$ que para que seja considerado o enriquecimento sem causa por fato ulterior que deixou de existir ou efeito que não se verificou, devem ser depreendidos os seguintes requisitos: (i) que a prestação seja destina à obtenção de resultado futuro, (ii) que seja possível entender a partir do negócio jurídico qual o fim daquela prestação e (iii) que o resultado almejado não se produza.

Doravante, Michelon $\mathrm{Jr}^{67}$ acrescenta que, em relação á causa, cabe, inicialmente, diferenciar a causa de atribuição da causa negocial. Esta trata da característica negocial, para que se possa saber se o negócio jurídico é válido ou-não e, doravante, é capaz de produzir efeitos. Já a justa causa de atribuição patrimonial é investigada de maneira mais geral, atinente ao fato de que a mesma deve unir três elementos, quais sejam, (i) uma posição jurídica, (ii) um bem e (iii) um indivíduo, podendo decorrer de várias formas jurídicas como o negócio jurídico, os modos de aquisição de propriedade e os atos administrativos.

O Autor ${ }^{68}$ classifica as causas de enriquecimento em três espécies, a saber: (i) causa que justifica atribuição patrimonial, (ii) causa que justifica um acréscimo de

\footnotetext{
66 AZEVEDO, Antônio Junqueira de. Novos estudos e pareceres de direito privado. São Paulo: Saraiva, 2010. p. 178-179.

${ }_{67}$ MICHELON JR, Claudio. Direito restitutório: enriquecimento sem causa, pagamento indevido e gestão de negócios. São Paulo: Revista dos Tribunais, 2007. p. 209-212.

68 MICHELON JR, Claudio. Direito restitutório: enriquecimento sem causa, pagamento indevido e gestão de negócios. São Paulo: Revista dos Tribunais, 2007. p. 214-217.
} 
valor de um bem e (iii) causa que justifique o uso, gozo ou fruição de um bem por alguém que não o seu proprietário.

A falta de causa, para Serpa Lopes, ${ }^{69}$ parte de um estado de direito preexistente, o qual deriva sem o necessário desenvolvimento padrão, que acarreta num ato ou negócio jurídico desprovido de força aquisitiva do elemento justificativo para a aquisição de um valor.

Também é pacífico que Michelon $\mathrm{Jr}^{70}$ trata a ausência de causa como matéria casuística, o que importa em dizer que não é possível estabelecer um rol taxativo de situações nas quais seja inquirida a ausência de causa. Entretanto, o Autor tenta suscitar algumas das formas que podem dar origem à ausência de causa, entre elas, (i) quando ocorre por iniciativa do enriquecido, em geral casos de intromissão em direito alheio ou consumo não autorizado de bens alheios, (ii) quando ocorre por iniciativa do empobrecido, conhecido como enriquecimento imposto, em casos de free aceptance do enriquecido, por exemplo, (iii) quando ocorre sem a iniciativa de nenhum dos sujeitos.

Quanto à ausência de causa, a priori, Varela ${ }^{71}$ estabelece as noções de causa em diferentes casos, a saber: (i) causa da prestação, (ii) causa da obrigação e (iii) causa das restantes deslocações patrimoniais. No caso da prestação, a causa jurídica é a própria relação jurídica que a prestação visa satisfazer. No caso da obrigação, trata-se do objetivo do negócio no qual está integrada a obrigação, num sistema de negócios de natureza causais, a lei identifica este objetivo, diferentemente dos casos de negócios abstratos.

Finalmente, no restante das deslocações patrimoniais, como os atos de intromissão e atos meramente materiais, não haveria causa posto que a lei define que o bem deve pertencer a outrem, fixando uma ordenação de bens, assim, por exemplo, não caberia ao vendedor de imóvel para duas partes diversas, manter o proveito de ambas, posto que o ordenamento não prevê tal ato, contudo, é possível que aquele que não tem título de propriedade, mediante posse prolongada, possa exigir titularidade do bem, uma vez que a lei define como aceitável a usucapião. ${ }^{72}$

Nos dizeres de Camara Alvarez e Ponce de Leon, ${ }^{73}$ o enriquecimento sem causa, para garantir sua aplicabilidade, encontraria limitação em duas hipóteses, quais sejam: (i) o enriquecimento que deriva da apropriação de utilidade a qual constituía direito

69 LOPES, Miguel Maria de Serpa. Curso de direito civil: fontes acontratuais das obrigações - responsabilidade civil. 4. ed., rev. e atual. Rio de Janeiro: Freitas Barros, 1995. v. 5, p. 72.

70 MICHELON JR, Claudio. Direito restitutório: enriquecimento sem causa, pagamento indevido e gestão de negócios. São Paulo: Revista dos Tribunais, 2007. p. 225-227.

71 ANTUNES VARELA, João de Matos. Das obrigações em geral. 3. ed. Coimbra: Livraria Almedina, 1970. p. 320-323.

72 Id. Ibid., p. 324/325.

73 CAMARA ALVAREZ, Manuel de la; PONCE DE LEON, Luis Diez-Picazo. Dos estúdios sobre el enriquecimento sin causa. Editorial Civitas S/A, Sem data. p. 96/100. 
alheio ou (ii) o enriquecimento que deriva da apropriação de utilidade a qual constituía atividade alheia. No primeiro caso, tratar-se-ia de uma complementação do próprio direito alheio, ao passo que permitiria a restituição de uma faculdade do próprio detentor do direito. No segundo caso, tratar-se-ia da restituição de provimentos resultantes da atividade alheia em seus domínios.

Nas considerações de Echeverría, ${ }^{74}$ não apenas a falta de justo título daria ensejo ao enriquecimento sem causa, mas também a ausência de título suficiente, ou seja, aquele título que, embora existente, apresente conteúdo desproporcional ou que acarrete em situação ilegal, como, por exemplo, nos casos em que alguém se enriquece desmedidamente em relação à outrem.

Importa salientar que Fabrega Ponce ${ }^{75}$ discorre ser possível a lei como título justificativo do enriquecimento, a partir do momento em que esta obriga a tolerar uma intervenção ou utilização de bem alheio. Não seria, deste modo, o enriquecimento sem causa uma regra superior às demais presentes no ordenamento jurídico.

\section{Crítica à norma de subrogação}

Para se compreender a inconsistência do ordenamento pátrio e consequente violação ao princípio que veda o enriquecimento sem causa nos casos de sub-rogação da seguradora aos direitos do segurado deve-se estabelecer certas premissas, a saber, (i) o entendimento geral da teoria dos seguros, (ii) a aplicação da norma de sub-rogação no Código Civil, de 2002 e, por fim, (iii) a incidência da teoria geral do enriquecimento sem causa neste caso.

Grosso modo, trata-se de caso em que a seguradora, após desembolsar o valor do prêmio devido ao segurado em caso de sinistro, sub-rogasse no direito do segurado de ter o dano reparado por quem o causou para ajuizar ação perante o suposto causador do dano. Tal instrumento é previsto no Código Civil, de 2002.

Para que seja entendida a inconsistência do caso, primordial se faz entender a teoria geral dos seguros.

Historicamente, o seguro nasce como uma forma de permitir o comércio e captação de recursos à longa distância, dirimindo os custos operacionais de cada ação. Assim, os riscos inerentes à possibilidade de perda ou eventual acidente não seriam percebidos apenas pelo acidentado, mas sim por uma coletividade de possíveis

74 ECHEVERRIA, Jose. La responsabilidad fundada en el enriquecimiento injusto y su proyección hacia los problemas ético-jurídicos y políticos. Revista Jurídica de la Universidad Interamericana de Puerto Rico, Santurce, v. 24, n. 2, p. 193-211. p. 207.

75 FABREGA PONCE, Jorge. El enriquecimento sin causa. Colombia: Plaza \& Janes, 1996. t. 1, p. 355. 
acidentados. Doravante, o agente poderia continuar suas atividades, o que não seria factível caso tivesse que suportar todos os gastos de uma perda de carga, por exemplo.

Exemplo clássico é o das expedições náuticas no período das grandes navegações. Num raciocínio simplista, cada dono de navio teria que arcar com seus prejuízos, o que significa dizer que no caso de um navio afundar ou se perder, o dono do mesmo teria perdido todo o seu capital, posto que perdera a carga de especiarias e o próprio navio. Todavia, os mesmos perceberam que o risco da navegação afetava a todos de maneira proporcional.

Diante de tal constatação uma mudança de paradigma foi firmada. Mais vantajoso seria que todos pagassem uma parcela de um prejuízo decorrente da perda de um navio do que o pagamento total do mesmo. Por exemplo, num grupo de 5 navios, dados apriorísticos demonstravam que um deles submergiria, sendo que a probabilidade de cada um seria de 20\%. Assim, antes da partida, cada um de seus responsáveis arcava com um valor mais palatável, ou seja, $20 \%$ do que representava a perda de um navio, formando um montante que seria utilizado para pagamento de um sinistro provável, incerto e futuro.

Com o decorrer da evolução histórica, esta atividade se tornou complexa, e o seguro passou a fazer parte das mais distintas atividades humanas. Seu sentido decorre do risco, fato incerto e futuro que ronda qualquer atividade humana, de que uma atividade dispendiosa para seu executante possa vir a não se concretizar, ou pior, gerar um prejuízo de grande monta. A melhor saída neste contexto seria dividir o fardo com outros tantos executantes daquela mesma atividade, todos tangenciados pela sombra do mesmo risco.

Tal atividade, que começa como uma união dos próprios segurados passa a ser controlado por uma entidade maior, qual seja, a seguradora. Para exercer sua função, a segurado pauta-se na teoria dos grandes números, na teoria das probabilidades e na dispersão de riscos, a fim de garantir que os riscos sejam suportados de maneira a se estabelecer um plano de equilíbrio entre o que se arrecada e o que se dispende para a cobertura de sinistros.

Pela teoria dos grandes números, a contabilidade das seguradoras reproduz a probabilidade do sinistro dentro de distintos grupos sociais. Por exemplo, numa determinada região sabe-se que, a cada ano, são batidos 50 carros e outros 30 são furtados ou roubados. Assim, divide-se o valor provável a ser dispendido nestes casos entre todos aqueles sujeitos dispostos a conter o risco da perda total do bem.

Obviamente, quanto maior e mais complexa a sociedade, maiores são os nichos de atuação da segurado, o que lhe possibilita dispersar seus riscos. Por exemplo, uma seguradora de casas situadas em regiões de alagamento, atua também em regiões nas quais a probabilidade de desastres naturais é remota. Assim, o montante é melhor dividido. 
Outra forma de dirimir riscos da própria atividade de seguros é a contratação de um co-seguro, conhecido como resseguro que, como explica Fábio Ulhoa, ${ }^{76}$ decorre do risco existente na liquidação do seguro, provenientes de possível falha dos cálculos atuariais por erro humano ou então por casos fortuitos e outras eventualidades.

Ademais, a política das seguradas faz com que sejam cobrados prêmios diferentes para cada tipo de segurado, dependendo do risco e probabilidade de sinistro. É extremamente comum nos casos de seguradora de veículos que prêmios maiores sejam cobrados de pessoas do sexo masculino, entre 18 e 25 anos, por causa de um maior risco calculado. Aliás, diversas cláusulas restritivas ao comportamento do segurado são acrescentadas, como, por exemplo, manter o veículo na garagem, emprestá-lo à grupos de risco, nas quais não haveria cobertura do seguro.

Como define Ascarelli, ${ }^{77}$ baseando-se nas ideias de Vivant, a execução sistemática do seguro elimina o caráter aleatório do caso isolado e faz surgir previsões fundadas nos cálculos dos grandes números, incluindo a previsão de número de sinistros.

Percebe-se que o fim próprio da segurado é garantir que haverá capital para segurar um sinistro possível - o que é denominado mútuo. Para além, nos valores arrecadados - os denominados prêmios - já são somados os custos operacionais das mesmas. Indubitável, portanto, que as seguradoras funcionam com prejuízo zero, acobertadas pela teoria dos grandes números e pela dispersão dos riscos.

Haveria, assim, uma divisão entre prêmio puro, ou seja, o valor para assegurar o pagamento de indenização decorrente de sinistro e o carregamento, que corresponde aos custos administrativos e lucro da seguradora. ${ }^{78}$

Segundo Fabio Ulhoa Coelho, ${ }^{79}$ a função do seguro seria, deste modo, socializar entre as pessoas expostas a determinado risco as repercussões econômicas de sua verificação. Caberia às seguradoras estimar a ocorrência dos fatos e cobrar um prêmio proporcional de cada segurado.

Todavia, para além de seu mecanismo de funcionamento, o Código Civil prevê uma outra fonte de captação de recursos para a seguradora, qual seja, o Art. 786 de preceitua que: Paga a indenização, o segurador sub-roga-se, nos limites do valor respectivo, nos direitos e ações que competirem ao segurado contra o autor do dano. §1o Salvo dolo, a sub-rogação não tem lugar se o dano foi causado pelo cônjuge do segurado,

76 COELHO, Fábio Ulhoa. Curso de direito comercial. 8. ed., rev. e atual. São Paulo: Saraiva, 2008. v. 3, p. 163.

77 ASCARELLI, Tulio. Problemas das sociedades anônimas e direito comparado. São Paulo: Quorum, 2008. p. 311 .

78 COELHO, Fábio Ulhoa. Curso de direito comercial. 8. ed., rev. e atual., São Paulo, Saraiva, 2008. v.3, p. 153.

79 Id. Ibid., p. 152. 
seus descendentes ou ascendentes, consangüineos ou afins. $\S 2$ ó ineficaz qualquer ato do segurado que diminua ou extinga, em prejuízo do segurador, os direitos a que se refere este artigo. Tal regra vale para os seguros de danos.

Assim, após pagar o valor acordado na apólice, pode a seguradora ajuizar ação de indenização - muitas vezes na forma de um pretenso direito de regresso - perante causador do dano. Por exemplo, num caso de sinistro automotivo, no qual a seguradora pagou uma apólice de R $\$ 5.000,00$, a mesmo pode cobrar tal valor dos envolvidos no acidente, em que pese o valor já estar devidamente coberto pelos prêmios auferidos ao longo do tempo, pelo segurado em específico e por todos os segurados standarts que não utilizaram os valores recolhidos.

Salta aos olhos a conclusão a que se pretende chegar. Em pleno Código Civil repousa uma norma que flagra uma evidente não utilização do principio de vedação ao enriquecimento sem causa. Afinal, a seguradora tem todos seus gastos cobertos pelos valores dos prêmios pagos pelos segurados. Qualquer valor acrescentado seria um locupletamento à seguradora sem um justo motivo.

Analise-se os pressupostos, seja na forma tradicional, seja na forma contemporânea e percebe-se que há enriquecimento da seguradora, uma vez que um valor pecuniário é auferido à seu patrimônio em decorrência da ação de indenização; há empobrecimento por parte do causador do dano, que tem seu patrimônio pecuniário diminuído, ou seja, enriquecimento foi à custa de outrem e há empobrecimento indireto em relação ao segurado, que, injustificadamente tem um direito sub-rogado; há nexo causal, representado pela ação de indenização que culmina na execução do valor, o que é prescindível para a teoria contemporânea; há falta de justa causa já que a lei concede um poder sub-rogado à seguradora que não lhe cabe, tendo em vista que seu fim esta resguardado nos valores do seu mútuo.

Percebe-se que a lei dá guarida a uma forma de enriquecimento sem causa, numa desconsideração completa do princípio de vedação ao enriquecimento sem causa.

Também deve ser considerado que o segurado tem extirpado um direito próprio, qual seja, ter ressarcido os gastos com o dano causado. Isto porque os parágrafos subsequentes do artigo deixam expresso que não poderá o segurado ajuizar ação face o causador do acidente, uma vez que isto impede o exercício da sub-rogação da seguradora.

Novamente, neste caso, o entendimento do enriquecimento sem causa é mal estabelecido. Em se tratando daquele que sofreu um dano por ação ou omissão de outrem, cabe ao segurado a respectiva ação de responsabilidade civil e posterior indenização, em que pese o senso comum creditar este fato à uma espécie de enriquecimento sem causa.

Não se pode considerar enriquecimento sem causa, posto que há causa latente, qual seja, a ação ou omissão do causador do acidente culmina no prejuízo do segurado. Dizer que o segurado tem seu valor resguardado pela seguradora e, por isso, 
não pode perseguir aquele que lhe causou dano é difundir uma injustiça no ordenamento jurídico, confundindo o universo jurídico e o universo não-jurídico. Isto por que, quando o segurado opta por um seguro, o mesmo paga, frisa-se, paga o valor do prêmio, que corresponde à sua cota parte num possível sinistro.

Portanto, equivale dizer que tal ato discricionário, corresponde a uma forma de poupança entre vários indivíduos que juntam forças para dirimir gastos. Por outro lado, um indivíduo que não tenha seguro de seu veículo ou casa, por achar que sua probabilidade de sinistro é remota, pode simplesmente guardar um valor mensal numa poupança, que poderá ser usada no caso de um sinistro.

Caso esse indivíduo utilize o valor poupado para cobrir seus gastos a priori, seria justo que não pudesse ajuizar ação face o causador do dano? Parece inconcebível uma resposta afirmativa no caso. Logo, não se pode penalizar um indivíduo por tentar diminuir seus prejuízos, já que o valor pago pela seguradora não advém de um assistencialismo qualquer, mas sim de contribuição compulsória do segurado.

Como preceitua Ascarelli, ${ }^{80}$ a essência do contrato do seguro é que o beneficiário do mesmo tenha um interesse segurável, e que este se interesse pela não ocorrência do sinistro. Trata-se de uma prevenção do segurado, na mesma medida em que previne-se aquele que mantém seu carro na garagem indefinidamente, ou que constitui poupança para pagar eventual prejuízo.

Evidente, portanto, que o art. 786 do Código Civil, de 2002, atenta ao princípio de vedação ao enriquecimento sem causa enquanto informador de todo o sistema jurídico. Necessário se faz, por fim, considerar que o que se viola é o princípio de vedação ao enriquecimento, não a norma posta, já que esta não pode ser aplicada, já que o próprio artigo maculado serve de pressuposto de causa para o enriquecimento da seguradora.

Percebe-se, portanto, que há violação do princípio de vedação ao enriquecimento sem causa no caso da sub-rogação da seguradora no direito do segurado e, ao mesmo tempo, não há violação do princípio no caso de permitir ao segurado que ingresse com ação de indenização face ao causador do dano.

Isso porque falta à seguradora a causa justa, uma vez que o ressarcimento deve ocorrer tendo em vista um prejuízo e, como é possível depreender do estudo da teoria dos seguros, não há prejuízo das seguradoras quando do pagamento em decorrência do sinistro.

Ademais, não se pode render ao argumento falacioso de que a justa causa advém da própria disposição legal - justa causa legal - vez que esta não apresenta qualquer

80 ASCARELLI, Tulio. Problemas das sociedades anônimas e direito comparado. São Paulo: Quorum, 2008. p. 306. 
justificativa plausível para sua existência, o que não a coaduna com o Ordenamento Jurídico Civil brasileiro.

Doravante, deve-se afastar o argumento que o segurado incorreria em enriquecimento sem causa no caso de ajuizar ação de ressarcimento contra o causador do dano, simplesmente por ter sido ressarcido anteriormente pela segurado. Não há razão para tal afirmativa, uma vez que não se pode admitir o pagamento do prêmio como uma vantagem dada ao segurado, mas sim como resultado do pagamento ininterrupto dos valores devidos à seguradora. $\mathrm{O}$ Direito não pode prejudicar aquele que é zeloso no trato do seu patrimônio.

Ajustificativa, ao que parece, para a manutenção de uma afronta ao princípio de vedação ao enriquecimento sem causa é o forte lobby exercido pelas seguradoras de dano nos mais diversos ramos, derivado do alto poder de barganha propiciado pela - triste ironia - soma de capital proveniente de seus segurados.

\section{Conclusão}

À guisa de considerações finais, podem-se estabelecer as seguintes premissas:

(i) O enriquecimento sem causa é visto pela doutrina brasileira com caráter dúplice, ou seja, é tanto norma posta, quanto princípio geral do sistema do Direito Civil pátrio. Isso sugere que o mesmo deve ser aplicado na própria construção das normas de direito civil, uma vez que é necessário que o ordenamento guarde a devida coesão entre suas normas e princípios.

(ii) $\mathrm{O}$ enriquecimento enquanto requisito para existência do enriquecimento sem causa deve ser analisado à luz do caso concreto, vez que seu conteúdo é aberto e depende da comprovação da vantagem da parte que enriquece, que pode ocorrer de diversas maneiras.

(iii) $\mathrm{O}$ empobrecimento da parte contrária, por sua vez, deve ocorrer à custa de outrem, mas não precisa, necessariamente ser visível, podendo ser indireto ou invisível, a depender do caso concreto.

(iv) Já o nexo causal pressupõe uma aglutinação entre o enriquecimento e o empobrecimento, de forma que uma deriva e seja derivado do outro, podendo ocorrer diretamente ou indiretamente.

(v) Por fim, a ausência de justa causa deriva da ausência de elemento justificativo, podendo ser, à titulo de exemplo, lei, decisão legal, ato jurídico e fato social.

(vi) Derradeiramente, combinados os requisitos do enriquecimento sem causa às particularidades da norma de sub-rogação da seguradora ao direito de reparação 
do dano do segurado, tem-se claro que tal previsão afronta a vedação ao enriquecimento sem causa enquanto princípio informador do ordenamento jurídico brasileiro.

(vii) No caso da sub-rogação da seguradora em direito do segurado, entendido os pressupostos da teoria dos seguros e a natureza dos mesmos, percebe-se que a pretensa Ação de Regresso que se estabelece pelo Código Civil é forma de enriquecimento sem causa no tocante às seguradoras de danos, haja vista que seus custos estão resguardados pelo prêmio pago pelos segurados. Ademais, não seria caso de enriquecimento sem causa fosse a ação proposta pelo segurado, que tem direito de reparação, já que o seguro não o exime de pagamento e prejuízo em casos de acidentes, uma vez que apenas repassa uma quantia rateada e paga anteriormente pelo segurado, como se fosse mera poupança do mesmo.

(viii) Conclui-se, portanto, que o enriquecimento sem causa ainda não atingiu sua aplicação mais eficiente dentro do Ordenamento Jurídico brasileiro - podendo ainda ser melhor adequado.

(ix) Assim, por fim, ainda que podendo ser melhor aplicado, o enriquecimento sem causa resta presente em toda a relação humana, desde o mais simples preceito moral até à norma subsidiária no ordenamento jurídico, o que permite afirmar ser este um instituto necessário ao melhor desenvolvimento do direito, enquanto ciência social aplicada.

Campinas, 15 de junho de 2013.

\section{Referências}

ASCARELLI, Tulio. Problemas das sociedades anônimas e direito comparado. São Paulo: Quorum, 2008. p. 306.

ANTUNES VARELA, João de Matos. Das obrigações em geral. 3. ed. Coimbra: Livraria Almedina, 1970 .

AZEVEDO, Antônio Junqueira de. Novos estudos e pareceres de direito privado. São Paulo: Saraiva, 2010.

BARBIERA, Lelio. L'ingiustificato arricchimento. Napole: Joveni, 1964.

BOBBIO, Norberto. Teoria geral do direito. 2. ed. São Paulo: Martins Fontes, 2008.

CAMARA ALVAREZ, Manuel de la; PONCE DE LEON, Luis Diez-Picazo. Dos estúdios sobre el enriquecimento sin causa. Editorial Civitas S/A, s.d.

CAPUCHO, Fábio Jun. O enriquecimento sem causa no código civil brasileiro. 2007. Dissertação (Mestrado) - Faculdade de Direito, Universidade de São Paulo, São Paulo. 
COELHO, Fábio Ulhoa. Curso de direito comercial. 8. ed., rev. e atual. São Paulo: Saraiva, 2008. v. 3.

ECHEVERRIA, Jose. La responsabilidad fundada en el enriquecimiento injusto y su proyección hacia los problemas ético-jurídicos y políticos. Revista Jurídica de la Universidad Interamericana de Puerto Rico, Santurce, v. 24, n. 2, p. 193-211.

FABREGA PONCE, Jorge. El enriquecimento sin causa. Colombia: Plaza \& Janes, 1996.

FRANCISCO, Caramuru Afonso. O enriquecimento sem causa nos contratos. In: BITTAR, Carlos Alberto (Org.). Contornos atuais da teoria dos contratos. São Paulo: Revista dos Tribunais, 1993.

GORDLEY, James. Foundations of private law: property, tort, contract, unjust enrichment. Oxford: Oxford University Press.

HILDEBRAND, Lucas Fajardo Nunes. Pressupostos da obrigação de restituir o enriquecimento sem causa no código civil brasileiro. 2010. Dissertação (Mestrado) - Faculdade de Direito, Universidade de São Paulo, São Paulo.

LOPES, Miguel Maria de Serpa. Curso de direito civil: fontes acontratuais das obrigações responsabilidade civil. 4. ed., rev. e atual. Rio de Janeiro: Freitas Barros, 1995. v. 5.

MICHELON Jr., Claudio. Direito restitutório: enriquecimento sem causa, pagamento indevido e gestão de negócios. São Paulo: Revista dos Tribunais, 2007.

MONTEIRO, Washington de Barros. Curso de direito civil: direito das obrigações. Rev. e atual. São Paulo: Saraiva, 2003. v. 5.

NANNI, Giovanni Ettore. Enriquecimento sem causa. 2. ed. São Paulo: Saraiva, 2010.

NORONHA, Fernando. Enriquecimento sem causa. Revista de Direito Civil, Imobiliário, Agrário e Empresarial, São Paulo, v. 15, n. 56, p. 51-78. p. 57.

RAO, Vicente. O direito e a vida dos direitos. 6. ed., atual. São Paulo: Revista dos Tribunais, 2004. VIEIRA GOMES, Júlio Manuel. O conceito de enriquecimento, o enriquecimento forçado e os vários paradigmas do enriquecimento sem causa. Coimbra: Coimbra Editora, 1998. 